\title{
MODES OF FOREIGN ENTRY: A TRANSACTION COST ANALYSIS AND PROPOSITIONS
}

\author{
Erin Anderson* and Hubert Gatignon** \\ The Wharton School \\ University of Pennsylvania
}

\begin{abstract}
A "frontier issue" in international marketing is the appropriate choice of entry mode in foreign markets. The objective of this paper is to offer a transaction cost framework for investigating the entry mode decision. This framework provides 1) a theoretical basis for systematically interrelating the literature into propositions, 2) propositions about interactions which resolve the apparently contradictory arguments advanced to date. Specifically, the paper:

- illustrates the feasibility of clustering 17 entry modes into the degree of control the mode provides the entrant;

- proposes that the most appropriate (i.e., most efficient) entrymode is a function of the tradeoff between control and the cost of resource commitment

- advances testable propositions delimiting the circumstances under which each mode maximizes long-term efficiency.

The entry mode literature is reviewed in the context of these propositions, and guidelines are derived for choosing the appropriate mode of entry, given certain characteristics of the firm, the product, and the environment.
\end{abstract}

\footnotetext{
*Erin Anderson is Assistant Professor of Marketing at the Wharton School, University of Pennsylvania, which she joined in 1981. She received the Ph.D. from the UCLA Graduate School of Management. She has published in the Rand Journal of Economics, Marketing Science, and the Sloan Management Review.

**Hubert A. Gatignon has been an Assistant Professor of Marketing at the Wharton School, University of Pennsylvania since 1981. He obtained an MBA from UCLA in 1975 and a Ph.D. in Management from UCLA in 1981. Professor Gatignon has published in Marketing Science, the Journal of Marketing Research, the Journal of Consumer Research, and the Journal of Marketing.

The authors gratefully acknowledge the financial support of the Wharton Center for International Management Studies. The comments of Yoram Wind, Jean-Francois Hennart, and three anonymous reviewers, as well as Charles Goodman and Leonard Lodish, are greatly appreciated, as is the assistance of Shari Powell.
}

Received: August 1985; Revised: November 1985 \& March 1986; Accepted: March 1986. 
A firm seeking to perform a business function (e.g., production management, distribution) outside its domestic market must choose the best "mode of entry" (institutional arrangement) for the foreign market. The would-be entrant faces a large array of choices, including: a wholly-owned subsidiary, a joint venture (in which the entrant could be majority, equal, or minority partner), or a nonequity arrangement such as licensing or a contractual joint venture.

The impact of entry modes on the success of foreign operations is great, leading Wind and Perlmutter (1977) to identify entry modes as a "frontier issue" in international marketing. Entry modes differ greatly in their mix of advantages and drawbacks. The tradeoffs involved are difficult to evaluate and little understood. Several surveys of how firms actually make the entry mode decision (reviewed in Robinson 1978) indicate that few companies make a conscious, deliberate cost/benefit analysis of the options.

What is the best mode of entry for a given function in a given situation? Despite the existence of relevant evidence, the literature does not suggest how the manager should weigh tradeoffs to arrive at a choice that maximizes risk-adjusted return on investment. Instead, much of the literature contains many seemingly unrelated considerations, with no identification of key constructs. Often, a consideration is mentioned as part of a case study, with little indication of how the factor should affect other situations. Further, relevant work is scattered across books and journals in several disciplines, obscured by varying terminology, and separated by differences in problem setup, theory, and method. ${ }^{1}$

The objective of this paper is to develop a theory, expressed in testable propositions, for integrating the literature on entry into a unified framework. The theory, which comes from industrial organization, is explicitly concerned with weighing tradeoffs and with maximizing an economic criterion: long-term efficiency. In particular, the theory includes interactions between determinants of entry modes, interactions that help resolve contradictory arguments in the literature.

This review develops testable propositions concerning the following question: Under what circumstances is an entry mode the most efficient choice in the long run? Efficiency in general terms is the ratio of output to input. In the international context we mean the entrant's long-run return on its investment in an entry mode, adjusted for risk. Hence, we address the impact of a mode on both the numerator (returns) and denominator (investment) over the long-time horizon. ${ }^{2}$

Section one of this paper categorizes modes of entry into varying degrees of control by the entrant. Section two presents a transaction cost theory of entry modes, which generates a set of propositions. Entry mode research is reviewed in the context of these propositions. The paper concludes with suggestions for empirical research. 


\section{MODES OF ENTRY AND CONTROL}

The classical approaches to long-term strategic decisions, such as entry mode choice, emphasize choosing the option offering the highest riskadjusted return on investment in the feasible set. Yet, the literature on the entry mode choice makes little direct mention of risk or return. Instead, the issue is structured in terms of the degree of control each mode affords the entrant (Daniels, Ogram, and Radebaugh 1982, Robinson 1978, Robock, Simmonds, and Zwick 1977, Vernon and Wells 1976). But why such emphasis on control?

\section{The Preeminent Role of Control}

Control (the ability to influence systems, methods, and decisions) has a critical impact on the future of a foreign enterprise. Without control, a firm finds it more difficult to coordinate actions, carry out strategies, revise strategies, and resolve the disputes that invariably arise when two parties to a contract pursue their own interests (Davidson 1982). Further, the entrant can use its control to obtain a larger share of the foreign enterprise's profits. In short, control is a way to obtain a higher return.

Yet control, while obviously desirable, carries a high price (Vernon 1983). To take control, the entrant must assume responsibility for decisionmaking, responsibility a firm may be unwilling or unable to carry out in an uncertain foreign environment. Control also entails commitment of resources, including high overhead. This in turn creates switching costs, reducing the firm's ability to change its institutional arrangement should its choice turn out to be suboptimal. Resource commitment also increases the firm's exposure, i.e., the possibility of losses due to currency changes (Davidson 1982). Thus, to assume control is also to assume some forms of risk.

Control, then, is the focus of the entry mode literature because it is the single most important determinant of both risk and return. High-control modes can increase return and risk. Low-control modes (e.g., licenses and other contractual agreements) minimize resource commitment (hence risk) but often at the expense of returns. Firms trade various levels of control for reduction of resource commitment in the hope of reducing some forms of risk while increasing their returns. Hence, focusing on control is consistent with the classical risk-adjusted return perspective.

The viewpoint adopted in this paper is that international entry mode choices are most usefully and tractably viewed as a tradeoff between control and the cost of resource commitments, often under conditions of considerable risk and uncertainty. Preserving flexibility should be a major consideration of most firms in making the tradeoff. Flexibility, the ability to change systems and methods quickly and at a low cost, is always an important consideration, particularly in lesser-known foreign markets (where the entrant is likely to change systems and methods as it learns the 
new environment). This view is consistent with Holton (1971), who argues that control, risk, and flexibility are principal considerations (Mascarenhas 1982).

\section{Classifying Modes of Entry}

The objective of this review is to suggest major factors that determine what degree of control maximizes long-run efficiency. The theory of the efficiency of modes of entry treated in section two relies on the existence of a mapping to a control dimension but not on any particular mapping. For purposes of illustration, we suggest, in this section, a mapping from entry modes to the degree of control they afford the entrant.

As a caveat, there are many ways to gain control and many variations within any one form of entry mode (Kindleberger 1984, Hayashi 1978). For example, a minority partner might exercise influence out of proportion to ownership, due to such factors as a special contractual arrangement, expertise, or status as a government body. Hence our discussion is very general, and exceptions to our mapping can be found. Consequently, this discussion is intended to demonstrate the feasibility of a mapping, empirical tests of which are independent from the theory proposed in section two. Indeed, a valuable research contribution would be the development of a detailed theory of the relationship between control and governance structure.

\section{A Suggested Clustering of Entry Modes}

Although there is no tested, accepted theory as to how much control each entry mode affords, both the "management" (Root 1983) and the "economic" (Calvet 1981, Caves 1982) streams of research offer information as to the clustering of entry modes. Figure 1 illustrates how 17 entry modes can be grouped in terms of the amount of control (high, medium, low) an entrant gains over the activities of a foreign business entity.

As shown in Figure 1, dominant equity interests (wholly-owned subsidiary or majority shareholder) are expected to offer the highest degree of control to the entrant (Root 1983, Davidson, 1982, Bivens and Lovell 1966, Friedman and Beguin 1971, Killing 1982).

Balanced interests (plurality shareholder, equal partnership and balanced contracts) are shown as medium-control modes based on the notion of a "credible commitment" (Williamson 1983) or "hostage." Firms forming a venture with a high likelihood of trouble (such as equal partnerships) will have difficulty locating a suitable partner. To attract a partner, the entrant may need to put up something to lose, a sort of good-faith collateral, known as credible commitment. For example, in a slightly unbalanced venture, the over 50\%-partner may concede favorable contract clauses (such as veto power). These clauses can be so favorable that a firm may have more control with a $49 \%$ share than a $51 \%$ share (Friedman and Beguin 1971). Or the commitment may be the most critical positions in the 
Figure 1

\section{Entry Mode Classified by the Entrant's Level of Control}

High-Control Modes: Dominant Equity Interests

Wholly-owned subsidiary

Dominant shareholder (many partners)

Dominant shareholder (few partners)

Dominant shareholder (one partner)

Medium-Control Modes: Balanced Interests

Plurality shareholder (many partners)

Plurality shareholder (few partners)

Equal partner (50/50)

Contractual joint venture

Contract management

Restrictive exclusive contract

(e.g., distribution agreement, license)

Franchise

Nonexclusive restrictive contract

Exclusive nonrestrictive contract

Low-Control Modes: Diffused Interests

Nonexclusive, non restrictive contracts

(e.g., intensive distribution, some licenses)

Small shareholder (many partners)

Small shareholder (few partners)

Small shareholder (one partner)

foreign entity: the exposed partner can demand to fill them with its own personnel, a method preferred by Japanese multinationals (Hayashi 1978).

In a 50-50 relationship, the hostage is a peculiar one - the venture itself. Friedman and Beguin (1971) point out that equality in equity capital can "lend a special feeling of partnership to the two partners" (p. 372), adding "the risk of deadlock itself acts as a powerful incentive to the partners, encouraging them to find solutions to disagreements by discussion and compromise" (p. 377).

In certain nonequity modes, moderate control comes from daily involvement in the operation and from expertise. These modes include:

- Contract management (an ongoing relationship) in which the entrant performs specified functions and in which the entrant has representation on the management committee that oversees the venture's activities,

- Contractual joint ventures,

- Restrictive exclusive contracts,

- Franchising (a form of licensing in which the use of a business system is granted). ${ }^{3}$ Franchising offers medium control because the typical agreement includes incentives to adhere to the system's rules and allows a high degree of monitoring of the franchisee's activities. 
- Contracts that are exclusive but nonrestrictive or nonexclusive but restrictive. Either restrictiveness or exclusivity give the entrant moderate control, though by different means. Restrictive contracts circumscribe the other party's freedom of action, while exclusive contracts (simultaneously a reward and a protection against competition) motivate the other party to cooperate (Stern and El-Ansary 1982).

Low-control modes are ones in which the entrant has diffused interests. These include nonexclusive, nonrestrictive contracts (multiple unrestricted licenses and intensive distribution) and minority equity positions.

We reiterate here that there are many ways to gain control. Our list is not exhaustive: In particular, we note that entrants may build stable relationships or networks with other parties in which the long-term interests of both parties allow the development of norms. Although this area has received relatively little research attention, developments have been made by Hakansson (1984) and Williamson (1985).

We now turn to propositions concerning the degree of control that is most efficient for a variety of conditions. Given a ranking of entry models on control, it is then possible to recommend an entry mode for a given entry situation.

\section{A TRANSACTION COST ANALYSIS OF FOREIGN MODES OF ENTRY}

What is the best entry mode for a given setting? Obviously, a large number of factors bear on the answer. The intent of this review is to propose constructs and mechanisms derived from a unified theoretical framework. This framework is similar to the general approach of several new theories of foreign investment (Kindleberger 1984, Caves 1971, 1982, Hennart 1982, Rugman 1982), which concern why multinational firms exist. In this paper, we develop these theories for one specific issue: choice of mode of entry. Our analysis builds on the existing literature by proposing detailed relationships between constructs corresponding to the ideas presented in the more general theories. As we develop these empirically testable propositions, we contrast them with predictions from other, frequently more well-known frameworks to suggest how they differ and to spur empirical research designed to sort out competing predictions. We also review findings that bear on each proposition.

Our mapping from governance structure to control (Figure 1) looks something like a progression from less integrated to more integrated. Williamson (1979) suggests that degree of integration proceeds from complete non-integration (classical marketing contracting between two parties) to complete integration (one entity "contracts" internally to perform a function), passing through intermediate points. Underlying this progression is the transference of authority from paper (a contract) to entities (arbitrators, parties to a transaction), culminating in the consolidation of authority by one party. This progression of authority is a growing degree of control. 
Control and integration are closely related, since integration gives a firm legitimate authority to direct operations. Hence, we employ a theory of vertical integration to generate propositions about the desirability of various modes of entry offering various degrees of control. The theory, transaction cost analysis, combines elements of industrial organization, organization theory, and contract law to weigh the tradeoffs to be made in vertical integration (and by extension, degree of control) decisions.

We begin with the assumption that the market being entered has at least enough potential that the firm can recoup the overhead of a high-control entry mode. If this is not the case, high-control modes are not worth considering (Williamson 1979). However, for markets large enough to break even on the fixed cost of a high-control mode, the entrant has a choice to make. In these circumstances, the efficiency of an entry mode depends on four constructs that determine the optimal degree of control, following a transaction cost analysis. These constructs are:

1. transaction-specific assets: investments (physical and human) that are specialized to one or a few users or uses;

2. external uncertainty: the unpredictability of the entrant's external environment;

3. internal uncertainty: the entrant's inability to determine its agents' performance by observing output measures;

4. free-riding potential: agents' ability to receive benefits without bearing the associated costs.

Figure 2

A Transaction Cost Framework For Analyzing the Efficiency of Entry Modes

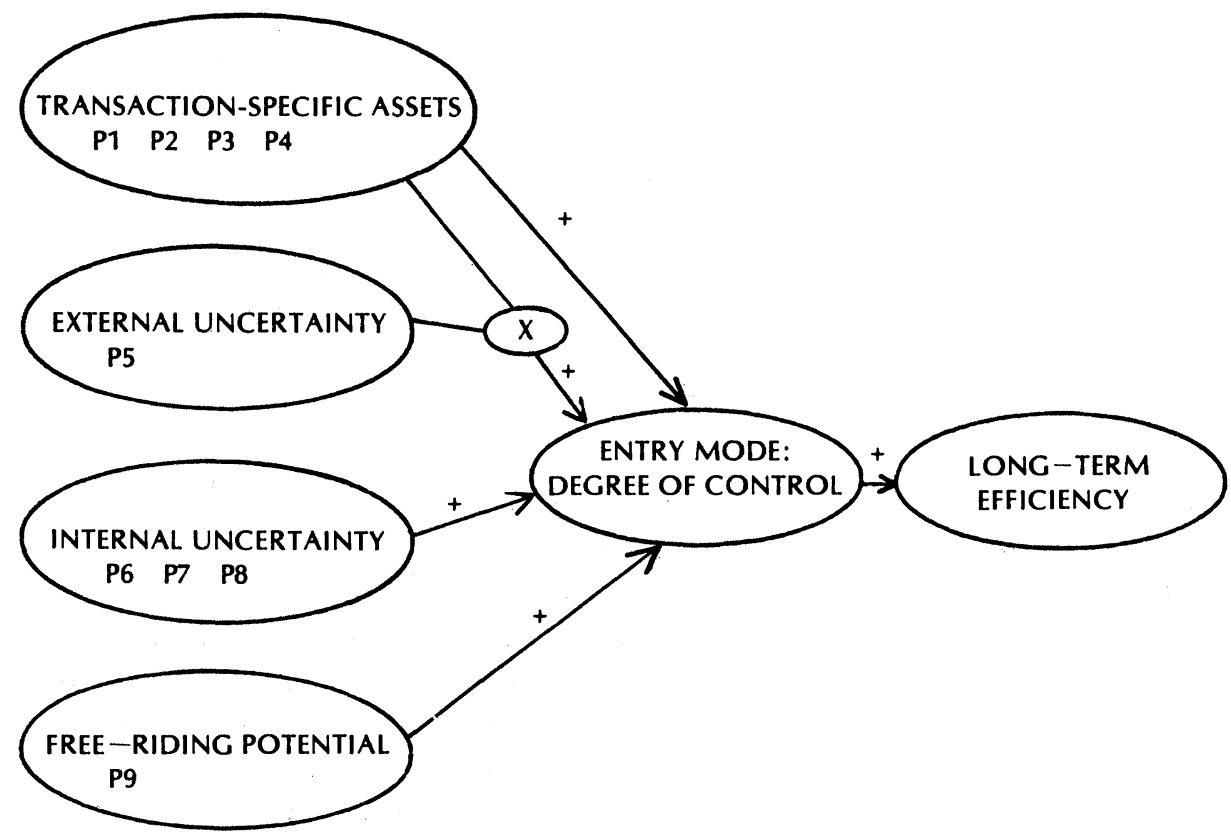


Figure 2 is an overview of the framework, which shows that these four factors should be positively associated with the entrant's degree of control. The four factors, their rationale, and their corresponding propositions about entry modes are discussed one by one in this section.

Figure 3 restates the propositions in a more accessible form and lists the conditions under which the modes in the high-control cluster are most appropriate.

\section{TRANSACTION-SPECIFIC ASSETS}

Transaction cost analysis approaches the entry mode question with the following promise: a low level of ownership is preferable until proven otherwise. We label this premise the "default" hypothesis.

The default hypothesis accords with an assumption fundamental to economics, that is, that market outcomes tend to be efficient when competition is strong. Competitive pressures drive parties to perform effectively at low cost and to deal with each other in fairness, honesty, and good faith lest they be replaced. Hayashi (1978) gives the example of foreign sales agents competing to carry out distribution for a Japanese entrant. Hayashi finds that where competition among agents is active, the resulting business relationship is highly cooperative. In general, where suppliers of a good or service are readily available, a firm may take advantage of their expertise and economies of scope and scale in performing their specialized function by writing a contract with one supplier, confident that a new supplier may be found if the relationship is unsatisfactory (Williamson 1981b). Accordingly, firms are advised to avoid integration whenever the supplier market is competitive. In this way, the firm can have both a high return and low risk.

By not integrating (or investing directly), a firm avoids the drawbacks of a company division. Overhead is minimized, as is company politics, communication distortion, and the possibility that an inside division will become obsolete or inefficient because it is shielded from the pressures of daily competition for contracts (Williamson 1975).

Integration (or direct investment) is, however, justified when the market mechanism no longer encourages performance, i.e., when competitive pressure is low. Williamson (1979) argues that most transactions begin when competition is intense but some degenerate into lock in ("small numbers bargaining") when the contract partner becomes irreplaceable. Then the partner may extract new contract terms, become inflexible, and otherwise violate the letter and spirit of the agreement ("opportunistic" behavior, i.e., self-interest seeking with guile) with relative impunity.

Degeneration into lock in occurs when "transaction-specific assets" of considerable value accumulate. These are investments (physical and human) that are valuable only in a narrow range of transactions, that is, specialized to one or a few users or uses (Williamson 1981b). An example of a physical transaction-specific asset is a stamping machine to make 


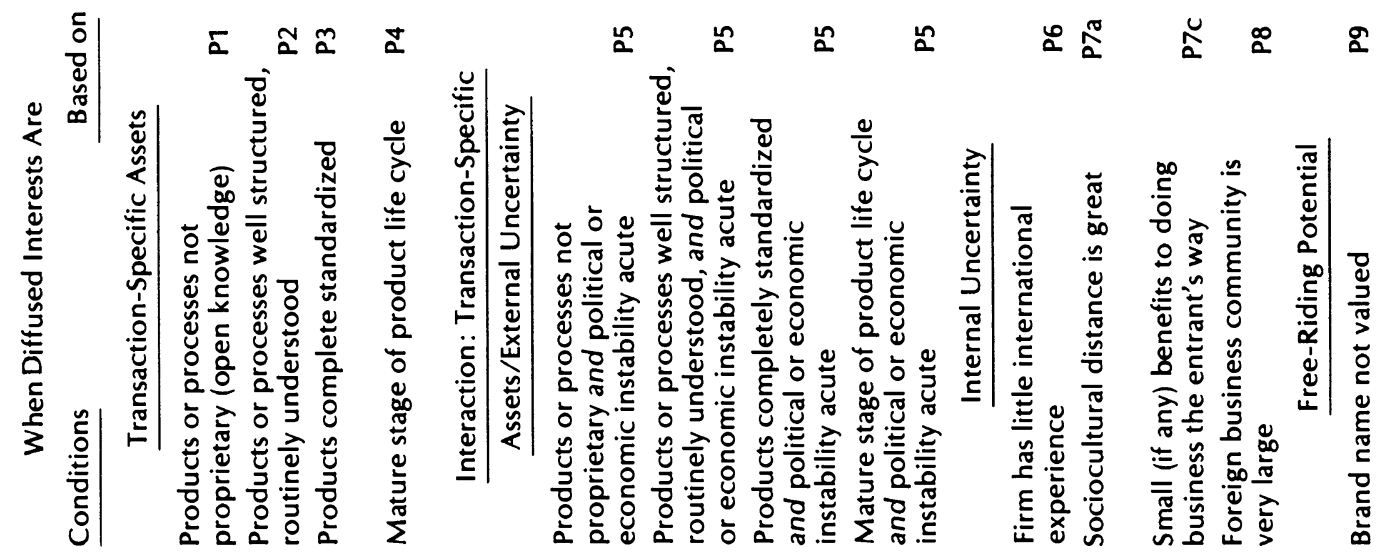

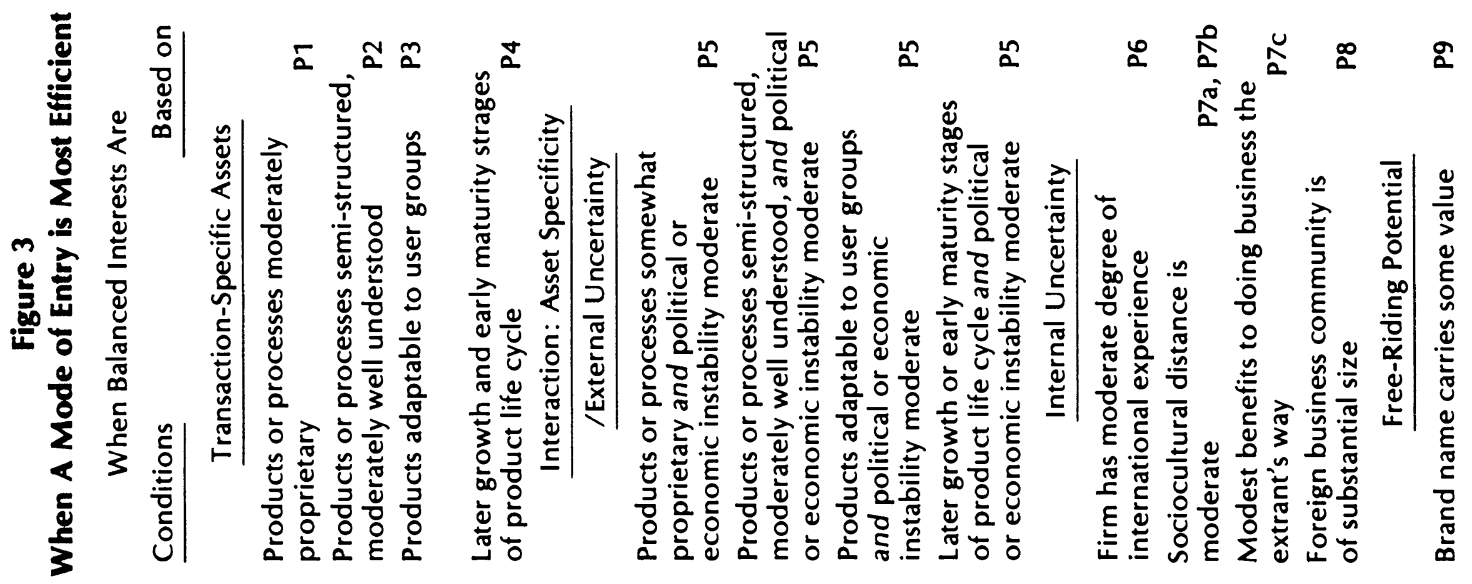

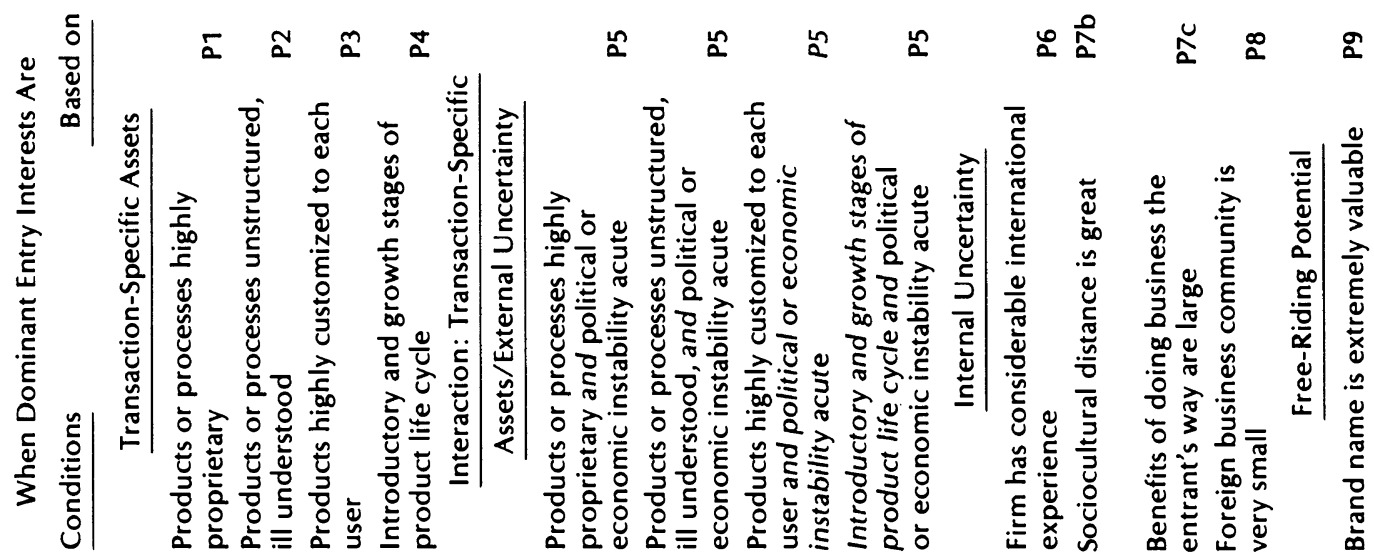


parts to the specifications of one manufacturer (Klein, Crawford, and Alchian 1972). Human transaction-specific assets include working relationships and knowledge of the idiosyncrasies of a firm and its activities. Transaction-specific assets usually develop over time, coming to assume a larger role the longer the transaction has continued. Frequently these experience-based assets are not very valuable. But where they significantly contribute to performance, the partner who acquires them becomes hard to replace.

When transaction-specific assets are likely to become valuable, transaction cost analysis suggests that firms are better off either integrating the function (exerting maximum control) or redesigning tasks so that general purpose assets will suffice. If the firm integrates, it will still become locked in, but to employees rather than outsiders. Opportunism can be combatted by exercising legitimate authority, monitoring behavior, and offering more varied incentives than can be used with outsiders. If instead the firm redesigns the task, it loses the value generated by specialized assets. However, both small numbers bargaining and overhead can be avoided, which sometimes offsets the loss of specialization benefits.

The preceding discussion has focused on ownership as a means of exerting control. More recent developments in transaction cost analysis (see Williamson 1985 for a summary) have begun to stress other ways to gain control, ways that fall in the large zone between classical market contracting and vertical integration. Many of the arrangements found in international operations fall into this zone (relational contracting). Research that explores the development of relational contracts promises to make a valuable contribution to our understanding of modes of entry (see Hakansson 1984).

We now turn to four propositions applying the notion of transactionspecific assets to the entry mode decision. The appropriate entry mode is a function of a number of variables taken simultaneously. For clearer exposition, our propositions deal with one factor at a time.

\section{Transaction-Specific Assets: Proposition 1}

The concept of transaction-specific assets suggests the following proposition:

P1: $\quad$ Modes of entry offering greater control are more efficient for highly proprietary products or processes.

Proprietary knowledge is an important type of specialized asset. On the surface, proprietary products and processes would seem appropriate for a low level of control, licensing, because there is something of value to license (Root 1983). Indeed, firms with high R\&D expenditures (which generate proprietary knowledge), do more licensing per se (Caves 1981). However, Calvet (1981) points out that proprietary knowledge is subject to hazards of transmission and valuation. Such knowledge is often ill codified and difficult to transmit across organizational boundaries. Furthermore, the classic problem of valuation of information arises: the 
buyer cannot know what the knowledge is worth (what bid to make) unless the knowledge is disclosed, at which point the acquirer need not pay for it. This obliges information-holders to exploit it themselves, resulting in high levels of ownership, and hence control, of a foreign business entity. Ownership has the added advantage of encouraging teamwork and keeping the (employee) team together (Williamson 1981b).

If a particular practice is efficient and an industry is competitive, we may expect to see firms that have survived in that industry following the efficient practice (Lilien 1979). Hence, systematic practices that firms follow constitute information about what mode is efficient. In the entry mode literature, it appears that firms do exert more control as proprietary content increases. Research and development expenditures (which generate proprietary knowledge) increase the extent of licensing (Telesio 1979) but increase the extent of direct investment even more (Davidson and McFetridge 1984, Caves 1982, Davidson 1982). Stopford and Wells find a negative relationship between research and development expenditures and the proportion of subsidiaries organized as joint venture rather than wholly-owned subsidiaries. This implies that firms tend to reserve proprietary knowledge for entry vehicles they control completely. In a similar vein, Coughlan and Flaherty (1983) study the use of wholly-owned distribution (high control) vs. independent distribution (low control) by U.S. semiconductor manufacturers operating in foreign markets. They find that high control is more often employed for technically sophisticated products, which tend to have higher proprietary content than unsophisticated products. This corresponds to a finding in the literature on intrafirm trading, which considers the extent to which a multinational firm manufactures its own inputs and markets its own outputs. Intra-firm trade indicates that a firm not only is integrated (common ownership) but acts integrated (is self-sufficient). Hence, the forces that drive integration (high control) should also drive intra-firm trading (Lall 1978). Lall (1978) and Helleiner and Lavergne (1979) find that intra-firm trading is strongly related to R\&D spending, an oft-used proxy for proprietary content and technological sophistication.

\section{Transaction-Specific Assets: Proposition 2}

Another implication of the concept of asset specificity is:

P2: $\quad$ Entry modes offering higher degrees of control are more efficient for unstructured, poorly-understood products and processes.

It is particularly difficult to use low-control entry modes for more illstructured, poorly-understood activities and knowledge. Teece (1976) refers to a "common code" of understanding of what the problem and its parameters are. The common code of understanding is a transactionspecific asset that is critical for amorphous functions (Johanson and Vahlne 1977). Teece (1976), in a path-breaking empirical study of technology transfer costs, strongly supports this idea. He finds that the 
costs of the entrant's first transfer across national boundaries are much higher than the costs of subsequent transfers. This occurs because the first transfer is ill understood. Thus, development personnel must interact heavily with production personnel to solve the inevitable unforeseen problems. Fortunately, the firm moves down the learning curve by developing and codifying solutions, which are applied to subsequent transfers of this technology. For such ill-structured, poorly understood activities as first transfers of technology, high-control entry modes are preferable to preserve and extend the common code of understanding.

Teece (1983) suggests complexity is a proxy for the degree to which products and processes are ill-structured and poorly understood. In accordance with proposition 2, Wilson (1980) finds licensing (low control) is more common for simpler products, while direct investment (higher control) is more common for complex products. Davidson and McFetridge (1984) find that radical new products are more likely to be transferred to a virtually wholly-owned affiliate (at least $95 \%$ equity) than to an independent firm (less than 5\% equity).

\section{Transaction-Specific Assets: Proposition 3}

P3: $\quad$ Entry modes offering higher degrees of control are more efficient for products customized to the user.

Customized products demand considerable local knowledge. On the surface, this presents no difficulties, since the entrant can contract with a local independent entity that has that knowledge. But by the nature of customization, the entrant must work actively with the local entity to tailor the product to the user. Accordingly, working relationships must be developed between personnel from each company (contractor and contractee). Those relationships will include a knowledge of what to expect from individuals and of how to communicate. These working relationships constitute an asset specific to the contractor-contractee transaction. Holton (1971), Keegan (1974), and Kobrin et. al. (1980) note the strong reliance of decision-makers on such relationships when assessing other foreign opportunities, which underscores their importance. Since these relationships exist only with the current contractee, the entrant is locked in. Team effects have been created, and control is needed to preserve them (Williamson 1981b).

Johanson and Vahlne (1977) suggest that people-intensive tasks are particularly ill-structured. If so, we would expect such customized businesses as management consulting, banking, and advertising to be dominated by high-control entry modes. Caves (1981) surveys anecdotal evidence that service firms such as these are more likely than other firms to go abroad, often at the urging of domestic clients making their own international entries. Presumably, this occurs because clients want to preserve and extend the intimate knowledge and working relationship already built up with service firms. Weinstein (1974), in his survey of U.S. advertising agencies expanding abroad, finds over $60 \%$ of foreign affiliates 
are at least majority-owned by the parent agency. In distribution, Coughlan and Flaherty (1983) find high-control distribution methods used more often for products with high service requirements, a characteristic of customized products.

\section{Transaction-Specific Assets: Proposition 4}

P4: The more mature the product class, the less control firms should demand of a foreign business entity.

Immature product classes have a high proprietary content (Chandler 1977), raising the transmission and valuation problems mentioned earlier. Further, technological and market knowledge of a new product class is not yet common. Hence, only the innovator's personnel know the product and its markets. To avoid becoming locked in to outsiders who acquire that knowledge, control is required. Thus, newer technology is likely to be handled by wholly-owned subsidiaries (high control) (Williamson 1979).

Specialized knowledge comes into the open market as the innovation diffuses. Over time transaction-specific assets associated with an innovation become general purpose assets associated with a well-established product. Chandler (1977) documents this diffusion for products and processes that were an innovation in the U.S. in the nineteenth century. As this diffusion occurs, we should expect to see less integration, as less administrative control is needed. Hence, older technology is likely to be licensed or handled by a joint venture (lower control) (Williamson 1979). ${ }^{4}$

In the international entry mode literature, Weinstein (1974) finds that U.S. advertising agencies entered foreign markets beginning in 1915, when large-scale advertising was a novel way of doing business. Consistent with P4, Weinstein finds that the first advertising agencies going abroad were highly likely to start subsidiaries from scratch and to own them $100 \%$. In later years, when advertising became common, U.S. entrants became more likely to acquire existing firms and to take less equity, often minority positions.

Teece (1976) finds that technology transfer costs (absorbed by transferor and transferee) decline sharply in mature product classes (measured by the age of the technology and the number of competitors using similar or competing technology). Because the requisite knowledge is well codified and widely available for hire, the entrant does not need to supplement the control offered by the market mechanism.

This product class effect has been suggested for various reasons in the entry mode literature. One reason advanced is that the likely gains are lower with mature products, so that management will prefer investing resources in more promising sectors (Bivens and Lovell 1966). Another explanation is that firms with immature products are in a better bargaining position with local authorities. Because their product is difficult to duplicate, they can force host governments and local partners to grant them more ownership and control and do not need the expertise of 
partners (Bivens and Lovell 1966, Davidson 1982). As the product matures, the advantage erodes, creating pressure to give up control. Vernon (1977) calls this the "obsolescing bargain."

We now turn to propositions about the impact of external uncertainty, the second of the four transaction cost constructs, on the viability of entry modes.

\section{EXTERNAL UNCERTAINTY}

External uncertainty is the volatility (unpredictability) of the firm's environment. Williamson (1979) hypothesizes that firms should react to volatility by avoiding ownership, since it commits them to one operation that may not be appropriate when the next environmental shift occurs. Rather, firms should retain flexibility and shift risk to outsiders. This suggests that in the absence of transaction-specific assets, the default option, market contracting, is unchanged by volatility. We should not expect higher-control entry modes to be more efficient than lower-control modes in volatile settings.

But what if transaction-specific assets accumulate such that the entrant becomes locked in to a partner in a shifting environment? Then flexibility, the major reason not to integrate in the face of uncertainty, is lost anyway. Further, frequent shifts mean frequent negotiation of new arrangements, presenting the agent with many occasions to behave opportunistically and inflexibly. In short, uncertain environments aggravate the normal difficulty of working with irreplaceable agents, making the combination of uncertainty and specificity a potent double bind. This suggests that given some degree of asset specificity, control becomes more desirable as uncertainty increases.

This idea is represented in Figure 3. The horizontal line (no transactionspecific assets) indicates that without specificity (TSA), uncertainty should be unrelated to the degree of control sought. But given specificity, marked by an X,uncertainty increases the need for control. The strength of this relationship increases as specificity increases.

\section{External Uncertainty: Proposition 5}

In international operations, external uncertainty (unpredictability) is an important factor. External uncertainty is typically labeled "country risk," which can take many forms, e.g., political instability, economic fluctuations, currency changes (Herring 1983)..$^{5}$ Some writers argue that firms react to unpredictability by exerting control to manage their volatile affairs and resolve disputes (Killing 1982, Bivens and Lovell 1966). Unfortunately, this commits the entrant to an operation that may turn out to be inappropriate as unforeseen circumstances develop (Root 1983). Further, in volatile environments, a product or technology may be obsolete by the time a high-control administrative mechanism is in place. Hence, firms may license in fast-changing industries simply to get their returns before they disappear (Caves 1981). 
Transaction cost analysis suggests that in volatile environments, entrants are better off accepting low-control entry modes (the "default option"). This not only avoids resource commitment but frees entrants to change partners or renegotiate contract terms and working arrangements relatively easily as circumstances develop and change. ${ }^{6}$ Low control maintains flexibility - unless flexibility has already been lost through the accumulation of transaction-specific assets.

Hence:

P5: The greater the combination of country risk (e.g., political instability, economic fluctuations) and transaction-specificity of assets (proprietary content, poorly understood products, customization, product class immaturity), the higher the appropriate degree of control.

This proposition is an interaction, ${ }^{7}$ expressed as an $\mathrm{X}$ in Figure 2, and occurs in addition to the effect of asset specificity alone (propositions 1 through 4). An interaction implies that each source of unpredictability should interact to magnify (add to) the separate impact of each source of transaction-specific assets: the proprietary nature of products and processes $(\mathrm{P} 1)$, ill-understood products and processes ( $\mathrm{P} 2)$, customizing products to the user (P3), and the immaturity of a product class (P4). An entrant in these circumstances is likely to find the problems of managing irreplaceable agents magnified, since the risky, changing environment presents numerous occasions for agents to shirk and to renegotiate to their advantage.

In a nutshell, proposition 5 suggests that environmental unpredictability plays a major role when asset specificity is high, magnifying the need for control that specificity creates. When specificity is low, unpredictability does not change the default option, low control, for the firm can deal with unpredictability by changing agents. Instead of exerting control (and assuming the corresponding risk), the entrant can retain flexibility and let the competitive market mechanism operate to generate returns (Mascarenhas 1982).

\section{INTERNAL UNCERTAINTY}

The third factor in the transaction cost framework is internal uncertainty. Internal uncertainty exists when the firm cannot accurately assess its agents' performance by objective, readily available output measures. This may occur when good measures of output are not available, or when the relationship between inputs and outputs is ill-understood (Ouchi 1977), making it difficult to specify what performance level to expect. Uncertainty internal to the firm makes control more desirable regardless of the level of asset specificity involved (Williamson 1981a). When performance cannot be specified or measured easily, firms can monitor inputs rather than evaluate outputs. Further, firms can use a variety of subtle incentives to develop goal congruence and loyalty. Thus, employees may act in the firm's best interest even if a firm cannot precisely specify what to do. 
When internal uncertainty is high, control is needed to impose subjective judgement and to monitor inputs (behavior). This presupposes that management knows how people should behave and how to judge hard-toquantify results. In the domestic environment, this is likely to be the case, as management has learned to manage over time. But the international setting is another matter. Entrants new to the international setting are unlikely to know how to overcome internal uncertainty. Further, firms that operate in competitive industries and try to exert control before they know how to use it will make serious errors that should depress efficiency (Teece 1976, p. 46).

\section{Internal Uncertainty: Proposition 6}

Accordingly,

P6: The entrant's degree of control of a foreign business entity should be positively related to the firm's cumulative international experience.

Proposition 6 has been extensively discussed in the literature that describes what managers do (which may or may not be efficient). There is some indication that firms do behave according to this proposition. A popular conception in the international management literature is that of a firm as a humanlike entity, "maturing" (Stopford and Wells 1972) as it acquires experience in international markets. The international neophyte fears the unknown, consequently overstating risks and understating returns of international markets (Davidson 1980). Overly conservative, the firm avoids setting up a foreign business entity and merely exports (Bilkey 1978). With the limited experience of exporting, the firm gains confidence and becomes more aggressive in nondomestic markets, moving toward more direct investment rather than export (Bilkey 1978, Weston and Sorge 1972) or licensing (Telesio 1979).

Still hesitant, the firm selects nearby, culturally similar countries (Engwall 1984, Davidson 1980, Bilkey 1978). With experience comes enhanced understanding, competence, and confidence, as well as more accurate perception of foreign risks and returns. The firm enters more distant, different countries (Davidson 1980) and with new adventuresomeness acquires a taste for control, for active management of the entity (Root 1983). Unlike the neophyte firm, content to let someone else run the international side of the business, the more experienced firm is confident, assertive, desirous of control, and willing to take risks to get it. Further, the firm has probably set up a headquarters staff for international operations and is eager to get the most form this overhead (Davidson 1980, 1982). Accordingly, experience should lead to more control, which proposition 6 suggests is the most efficient outcome.

Proposition 6 is not without controversy in the descriptive literature. Conceivably, the relationship between international experience and the observed degree of ownership is negative, i.e., that inexperienced firms demand higher ownership levels than do more experienced firms. This 
argument is based on the ethnocentric orientation of many international neophytes. Ethnocentrism leads inexperienced firms to demand to have their own nationals in key positions, which is easier to achieve via ownership than negotiation (Weichmann and Pringle 1979). Over time, firms become comfortable with local differences, develop working relationships with local people, and become confident that they can use local expertise to their advantage. At this point, firms are more willing to delegate control (Shetty 1979), which is reflected in lower degrees of ownership.

This counter-argument is a market power proposal: it assumes that firms have the latitude to follow their preferences even if the result is inefficient. In contrast, transaction cost analysis assumes inefficient practices are extinguished by market pressures. This implies that in noncompetitive industries, we may observe that the entrant's degree of control is negatively related to the firm's international experience. In other words, an inefficient practice may be observed where managers have the slack to implement their preferences at the sacrifice of long-term results.

\section{Internal Uncertainty: Proposition 7}

A particularly potent form of internal uncertainty is created by sociocultural distance. The difference between home and host cultures, although difficult to measure, has intrigued researchers in the international area. It is often argued that the greater the sociocultural difference between home and host countries, the lower the degree of control an entrant should and does demand. This is explained by the higher uncertainty executives perceive in cultures that are truly "foreign" to them. Not knowing, being comfortable with, or even agreeing with the values and operating methods of the host country, executives may shy away from the involvement that accompanies ownership (Root 1983, Davidson 1980, 1982, Richman and Copen 1972). Uncertainty due to sociocultural distance may also cause executives to undervalue foreign investments (Root 1983). Further, transferring home management techniques and values is difficult where the operating environment is very dissimilar to that of the home country (Richman and Copen 1972, Alpander 1976). Finally, sociocultural distance also creates high information costs, which firms may avoid by turning management over to partners or licensees (Root 1983).

Goodnow and Hansz (1972) support this viewpoint in an empirical study of how much control large U.S. firms exert when going overseas. Via cluster analysis, they sort 100 countries into three groups that roughly correspond to increasing sociocultural distance from the United States. Goodnow and Hansz also group entry modes into three types: strong control/high investment, moderate control/modest investment, and weak control/low investment. They find firms reduce their control and investment as they move away from socioculturally similar countries.

Not all writers agree. The Conference Board (Bivens and Lovell 1966) suggests that some firms react to sociocultural distance by demanding 
rather than avoiding ownership so that they may impose their operating methods. Such firms do not trust local management or non-local partners and prefer the control to "do it their way." Richman and Copen (1972) point out that being foreign gives a firm latitude to be different, to break the rules of the local culture to a point, because foreigners are expected to do things differently. Hymer (1976) contends that local firms, because they do not have the disadvantage of operating in a foreign culture at a distance, will always outperform foreign firms unless the entrants have a distinctive advantage. On occasion operating methods that do not fit local culture will constitute the necessary advantage that enables foreigners to compete with locals on their home ground.

In short, the entry mode literature conflicts concerning the impact of sociocultural distance. Transaction cost analysis suggests both views are correct for the following reason. Sociocultural distance makes internal uncertainty very high, since the environment is unknown. Furthermore, an entrant transferring its operating procedures and methods to a very different setting will have to train its agents heavily. Once they learn the entrant's ways, agents will have acquired valuable knowledge and relationships that are of little use to other firms in that country, making these assets transaction-specific (see Richman and Copen for examples). Given that the management problems created by sociocultural distance are now aggravated by specificity, an entrant is better off to demand control.

Alternatively, the entrant may decide to give up the benefits of employing its own methods, design an operation that uses local (general purpose) methods, and have little control. This is the design reaction to the prospect of specific assets. With specificity designed out, the problems of sociocultural distance can be managed by transferring risk to external agents, thereby reducing flexibility. If the foregone specialization benefits are not too large, designing out specificity is the efficient solution.

Whick is the more efficient reaction to sociocultural distance: creating specificity and using a high-control mode or designing out specificity ("going native") and using a low-control mode? The answer depends on the gains from doing business in unconventional foreign ways for a given culture. Transaction cost analysis suggests the effect of cultural differences is as follows:

P7: When sociocultural distance is great:

a: Low-control levels are more efficient than intermediate levels;

b: High-control levels are more efficient than intermediate levels;

c: High-control levels are more efficient only when there is a substantial advantage to doing business in the entrant's way.

Proposition $7 \mathrm{c}$ suggests that when operating in a very different environment, "our way" is not automatically the best way. Put differently, the 
default option, low control, should not be given up without a reason. Proposition 7b reflects the control reaction to sociocultural distance: a firm running an operation in a very different culture is bound to manage "our way," thereby creating specificity. The control that created lock in is now needed to manage it, but the firm benefits from its freedom to operate unconventionally. In contrast, proposition $7 \mathrm{a}$ reflects the design reaction to sociocultural distance: lacking control, a firm manages "as it's done here," losing specialization benefits but avoiding lock in. Intermediate levels of control are undesirable because they offer the worst of both possibilities - neither freedom to be unconventional nor low commitment to be flexible.

As a corollary, entrants are unlikely to write contracts with outsiders that impose the entrant's style on the contractee. By so doing, the entrant would enter small numbers bargaining without gaining much control over the partner. A testable implication is that franchising, which by nature imposes a management style on an independent, should decline as sociocultural distance increases.

\section{Internal Uncertainty: Proposition 8}

Richman and Copen (1972) point out that the problems of sociocultural distance can diminish over time even if the culture is stable. This occurs because as more foreign firms enter the country, the pool of local personnel trained in these methods grows. Not only do firms train managers, but their presence arouses awareness, which in turn causes host-country nationals to obtain a business education abroad. The process is slow but has a cumulative effect (which Richman and Copen detail in the case of India). Eventually, the pool is large enough that an entrant finds enough local contractees available to constitute an open market in management skills. In short, these skills have diffused to become general purpose and readily available rather than narrowly available and specific to the few companies using them. This suggests:

P8: The larger the foreign business community in the host country, the lower the level of control an entrant should demand.

Proposition 8 occurs because over time the entrant will find multinational management skills widely available, in spite of sociocultural distance (Seidler 1972 details this process for the transfer of American-style accounting methods to less developed countries). This diffusion of skills removes a major barrier to licensing (a low-control mode), which is the unavailability of "suitable" local firms (Caves 1981). Hence, management of the foreign entity can be contracted out to a pool of knowledgeable personnel, not necessarily employees, who can be controlled by the threat of replacement. In this vein, Contractor (1984) finds evidence that licensing becomes more lucrative relative to direct investment as a country's indigenous technical capability increases. 


\section{FREE-RIDING POTENTIAL}

A potential control problem arises whenever one party can "free ride" on the efforts of others, receiving benefits without bearing costs. For example, McDonald's has charged its French franchisee with riding on the company's international goodwill and recognition to attract customers without maintaining the cleanliness standards that support the company name (Time 1981). Transaction cost analysis suggests that ceteris paribus, where the potential for free-riding ("demand externalities") is high, entry modes offering higher control are more efficient.

\section{Free-Riding Potential: Proposition 9}

This suggests:

P9: $\quad$ Entry modes offering higher degrees of control are more efficient the higher the value of a brand name.

When a brand name is valuable, short-term gains can be had at the expense of the long term. Firms will take control to protect their brand name from degradation by free-riders (Davidson 1982) or to prevent the local operation from using the name in an inconsistent manner, thus diluting or confusing the international positioning of the brand (Holton 1971). Caves (1981) highlights the danger of local partners, who have less to lose from degrading a brand than does the entrant. Caves reviews both anecdotal and survey evidence that firms demand higher ownership levels when standardization of the product's design, style, quality, and name is part of the entrant's strategy. Since the strategy depends on assurance of all the name connotes (a "goodwill asset" or "reputation effect"), quality control is critical and free-riding is especially damaging.

These findings suggest high control is appropriate for heavily advertised brands. However, there is some contradiction in the empirical literature. Lall (1978) and Helleiner and Lavergne (1979) find that high advertising levels are associated with low intra-firm trading (low integration, low control), suggesting that valuable brand names can be efficiently marketed via low-control entry modes. Their explanation is that heavily advertised products tend to be unsophisticated consumer goods, which many agents are capable of handling, making low control appropriate. This explanation is consistent with propositions 1 through 4 concerning transaction-specific assets.

Yet heavy advertising does make free-riding more likely and control more desirable. This situation illustrates the value of the default option (low control) in transaction cost analysis. Beginning from low-control modes, a firm is advised to exert more control for valuable brand names (e.g., more heavily advertised brands). Hence, a firm is better off franchising its heavily advertised brands rather than merely licensing them in nonrestrictive, nonexclusive fashion. However, the firm may not need to go so far as a joint venture or majority-owned affiliate. Proposition 9 proposes 
that more restraints be added (higher-control entry modes) as brand value increases, rather than proposing that high control is always appropriate. Hence proposition 9 fits the empirical literature and illustrates the control-flexibility tradeoff.

\section{STRATEGIES FOR EMPIRICAL TESTS}

The measurement strategy used by researchers to date has largely consisted of using single-item measures that are themselves proxy variables (e.g., R\&D spending to indicate the construct "extent of proprietary information"). This approach, which is practical in light of the difficulty of obtaining international data, has yielded promising results. Clearly, hypothesis testing would be even stronger if psychometric methods were used to develop composite measures of each construct, thereby reducing reliance on single-item measures of complex constructs. ${ }^{8}$ One advantage of this method is that the interpretability of findings using proxy variables would be greatly enhanced if they were embedded in a composite measure. Further, the proxy variable approach would be a stronger test if researchers were able to rule out alternative explanations by controlling for the impact of a greater range of covariates than is typical in entry mode studies.

These suggestions are particularly useful for researchers designing their own data collection instruments, which allows them greater degrees of freedom in their approach and provides a closer correspondence between theory and data (Williamson 1985). Outside the entry mode field, some research involving primary data collection has resulted in multi-item measures of transaction cost constructs. These measures are described in Walker and Weber (1984), Anderson (1985), and Anderson and Coughlan (1985).

An empirical test of transaction cost propositions is incomplete without the inclusion of two classes of predictor variables. One class concerns government restrictions, which narrow the feasible set of entry modes (Teece 1984). The other class concerns "production cost" factors, e.g., taxes, labor costs, and transportation costs. Ultimately, an efficient entry mode is based on the sum of production and transaction (governance) costs, given the feasible set. Production cost factors correlated with transaction cost factors will bias estimates of effects unless included as covariates. Further, a more complete picture of entry modes emerges when production factors are considered (Williamson 1985). ${ }^{9}$

A direct test of the long-term efficiency of an entry mode would be difficult to make. Efficiency data are highly proprietary and, even if obtainable, reflect potentially large short-run effects. We suggest that an appropriate and more tractable empirical research approach is to study prevailing practice (usage of entry modes) in competitive industries, which tend to extinguish inefficient choices (Lilien 1979). An example would be to predict the impact of explanatory variables on the odds of choosing a higher-control mode over a lower-control mode at a given point in time. 
An approach that is even closer to the long-term nature of the propositions is to study what practices survive over time (e.g., using a hazard rates model). Although the time dimension introduces new variables, it does approximate the working out of inappropriate choices.

\section{CONCLUSION}

The transaction cost propositions advanced here are not suggested as an all-inclusive answer. Other factors will of course enter and may be very powerful in some settings. As indicated earlier, the framework applies to an entry decision where the choice is real. For a firm already operating in a foreign market with an existing mode of operation, the concepts discussed in this paper are certainly relevant. However, additional factors related to switching costs must be considered. The proposed framework also has limited value in situations where governmental, competitive, or information restrictions eliminate a large number of options. Nonetheless, the transaction cost approach is a useful way to structure the issues. This is particularly helpful when dealing with poorly understood issues and a long list of potentially relevant variables whose direction of effect is difficult to predict.

Simplification is a critical first step when dealing with complex problems. Our analysís ignores or downplays considerations that play a major role in some settings. In particular, we assume that an entrant, having decided to operate in a given market, has a choice of entry modes. This ignores possible government restrictions and assumes the entrant is contemplating a volume of business sufficient to carry the overhead of a high-control entry mode, at least over the long run (Williamson 1979). Further, we do not consider possible interactions between decision to enter and choice of entry mode.

Finally, we assume the entrant wants to operate a profitable business venture in the host country. To the extent that a foreign operation's objectives may be subordinate to the strategy needs of a parent multinational, other objectives may take precedence. In turn, the multinational's need to trade off subsidiary profits for system profits obliges the MNC to exert more control than the transaction cost default option suggests (Caves 1982). In general, higher degrees of control are more appropriate for entrants that closely coordinate global strategies.

Given these limitations, what can be gained from the framework proposed here? Much of the literature on modes of entry does not suggest hypotheses but considerations. The pros and cons of, say, licensing, are weighed against an alternative that is usually unspecified. Hence, predictions are difficult to make. In contrast, the framework presented here yields testable propositions based on the control-resource commitment tradeoff. A notable advantage of transaction cost analysis in this regard is the "default" hypothesis: low-resource commitment is preferable until proven otherwise. The presence of a default hypothesis is especially helpful for theory testing because it provides a testable prediction. 
Transaction cost analysis has been extended in recent years to cover a range of control rather than the extremes of integrate or contract out (Williamson 1985). In this form, transaction cost analysis brings to the entry mode problem an emphasis on the growth of ties that bind, on uncertainty, on the balancing of risks (credible commitments)and on the scale of operations. These constructs have been used to bring together many of the diverse ideas (such as the effect of sociocultural distance) expressed in the managerial and economic literatures and order them into testable propositions under a consistent rationale. Some of these propositions are new (e.g., the effect of the foreign business community), while others serve to clarify debates in the literature (e.g., the effect of sociocultural distance). The propositions also emphasize the interactions derived from the transaction cost analytical framework. Other interactions could be observed in empirical work in the sense that the joint effect of two variables could be greater than the sum of their independent effects. However, the rationale for these interactions goes beyond a transaction cost analytical framework. While the approach is incomplete, it is a useful starting point in examining tradeoffs among modes of entry.

In this paper we have developed a systematic approach to the entry mode issue. The propositions summarized in Figures 2 and 3 are testable. It is hoped, these propositions will encourage empirical research into an important area, as well as provide guidelines to management about how to match entry modes with their situations.

\section{NOTES}

1. Caves (1982) and Hennart (1982) undertake ambitious surveys of both the economic and international business research on multinational enterprise, including the entry mode issue. This paper builds on their works. We develop testable propositions (involving tradeoffs and interactions) as to when each mode of entry is likely to be effective. This is made possible by adopting an explicit criterion of long-term efficiency and employing a transaction cost perspective.

2. The purpose of developing the theory presented here is to help managers choose which form of entry to employ in a foreign market. Therefore, the theory concerns only situations where there is a set of options from which to choose. Further, the long-term orientation confines us to durable entry modes. We do not address short-term contracting (e.g., nonrenewable one-year licenses). The longterm efficiency criterion does not apply to a short-term arrangement. Consequently, this analysis does not offer insight about the length of contract. Nonetheless, the long-term perspective is necessary when the firm makes a long-term commitment to a market. See Kindleberger (1984) for a discussion of long vs. short-term contracts.

3. Franchising arrangements are frequently exclusive as well.

4. A product class may have reached the mature stage in the entrant's home country but not the host country. Hence, indigenous capability is not yet widely available, and the entrant who contracts with and trains a local independent entity is creating transaction-specific assets. The relevant level of product maturity, therefore, is in the host country.

5. For practical purposes, risk and uncertainty are synonymous (Herring 1983).

6. Many firms choose to retain low resource commitment but trade off the renegotiation aspect of flexibility by writing long-term licenses.

7. Interactions are typically operationalized as a multiplication of two terms (here, specificity and uncertainty). The multiplicative term is high when both factors are high (combined presence) and low when either factor is low (lack of combined presence). Of course, both terms must be positive for the interaction to meanfully express the combined presence of two factors. 
8. Nunnally (1978) is perhaps the most cited reference on psychometric methods and offers concrete suggestions for overcoming the data limitations that are bound to arise in conducting field research.

9. Accounting for production costs is particularly important when considering introducing a new product line into a foreign market where the firm has an ongoing operation. While product addition is an entry, it is an incremental decision. Hence, it is the incremental costs that are relevant. For example, Davidson and McFetridge (1984) find that if firms have an affiliate in place, they are more likely to add product to the affiliate's line than to seek other arrangements. This is because the fixed costs of the affiliate have already been incurred; the additional operation generates only marginal costs.

\section{SELECTED REFERENCES}

Alpander, Guvenc G. (1976), Use of Quantitative Methods in International Operations by U.S. Overseas Executives, Management International Review, 10 (1), 71-77.

Anderson, Erin (1985), The Salesperson as Outside Agent or Employee: A Transaction Cost Analysis, Marketing Science 4 (Summer), 234-254.

and Anne T. Coughlan (1985), Distribution of Industrial Products Introduced to Foreign Markets: Independent Versus Integrated Channels, Working Paper 85-033, Department of Marketing, The Wharton School.

Bilkey, Warren J. (1978), An Attempted Integration of the Literature on the Export Behavior of Firms, Journal of International Business Studies, 9 (Spring-Summer), 33-46.

Bivens, Daren Kraus and Enid Baird Lovell (1966), Joint Ventures with Foreign Partners, New York: the National Industrial Conference Board.

Calvet, A.L. (1981), A Synthesis of Foreign Direct Investment Theories and Theories of the Multinational Firm, Journal of International Business Studies, 12 (Spring-Summer), 43-59.

Caves, Richard E. (1982), Multinational Enterprise and Economic Analysis, Cambridge: Cambridge University Press.

(1971), International Corporations: The Industrial Economics of Foreign Investment, Economica, 38, 1-27.

Chandler, Alfred D. (1977), The Visible Hand: The Managerial Revolution in American Business, Cambridge, Mass.: The Belknap Press.

Contractor, Farok J. (1984), Choosing Between Direct Investment and Licensing: Theoretical Considerations and Empirical Tests, Journal of International Business Studies, 15 (Winter), 167-188.

Coughlan, Anne T. and M. Therese Flaherty (1983), Measuring the International Marketing Productivity of U.S. Semiconductor Companies. In David Gautschi, ed., Productivity and Efficiency in Distribution Systems, 123-149, Amsterdam: Elsevier Science Publishing Co., Inc.

Dániels, John D., Ernest W. Ogram, Jr., and Lee H. Radebaugh (1982), International Business: Environments and Operations, 3d edition, Reading, Mass.: Addison Wesley.

Davidson, William H. (1982), Global Strategic Management, New York: John Wiley and Sons. (1980), The Location of Foreign Direct Investment Activity: Country Characteristics and Experience Effects, Journal of International Business Studies, 11 (Fall), 9-22.

Davidson, William H. and Donald G. McFetridge (1984), International Technology Transactions and the Theory of the Firm, The Journal of Industrial Economics, 32 (March), 253-264.

Eiteman, David K. and Arthur I. Stonehill (1973), Multinational Business Finance, Reading, Mass.: Addison-Wesley

Engwall, Lars (1984), ed., Uppsala Contributions to Business Research, Uppsala, Sweden: Acta Universitatis Upsaliensis.

Evan, William M. (1965), Toward A Theory of Inter-Organizational Relationships, Management Science, 11 (August), B-217-B-230.

Friedmann, Wolfgang G. (1972), The Contractual Joint Venture,Columbia Journal of World Business, 7 (January-February),57-63.

Friedmann, Wolfgang G. and Jean-Pierre Beguin (1971), Joint International Business Ventures in Developing Countries, New York: Columbia University Press.

Goodnow, James D. and James E. Hanz (1972), Environmental Determinants of Overseas Market Entry Strategies, Journal of International Business Studies, 3 (Spring), 33-50. 
Hackey, D. (1976), The International Expansion of U.S. Franchise Systems: Status and Strategies, Journal of International Business Studies, 7 (June), 65-75.

Hakansson, Hakan (1984), ed., International Marketing and Purchasing of Industrial Goods, New York: John Wiley and Sons.

Hayashi, Kichiro (1978), Japanese Management of Multinational Operations: Sources and Means of Joint Venture Control, Management International Review, 18 (4), 47-57.

Helleiner, G.K. and Real Lavergne (1979), Intra-Firm Trade and Industrial Exports to the United States, Oxford Bulletin of Economics and Statistics, 41 (November), 297-311.

Hennart, Jean-Francois (1982), A Theory of Multinational Enterprise, Ann Arbor: The University of Michigan Press.

Herring, Richard J., ed. (1983), Managing International Risk, Cambridge: Cambridge University Press.

Holton, Richard (1971), Marketing Policies in Multinational Corporations, California Management Review, 13 (4), 57-67.

Hymer, Stephen (1976), The International Operations of National Firms, Cambridge: MIT Press.

Johanson, Jan and Jan-Erik Vahlne (1977), The Internationalization Process of the Firm - A Model of Knowledge Development and Increasing Foreign Market Commitment, Journal of International Business Studies, 8 (Spring-Summer), 23-32.

Keegan, Warren J. (1974), Multinational Scanning: A Study of the Information Sources Utilized by Headquarters Executives in Multinational Companies, Administrative Science Quarterly, 19 (September), 411-421.

Killing, J. Peter (1982), How to Make A Global Joint Venture Work, Harvard Business Review, 60 (May-June), 120-127.

Kindleberger, Charles P. (1984), Multinational Excursions, Cambridge: The MIT Press.

Klein, Benjamin, Robert G. Crawford, and Armen A. Alchian (1972), Vertical Integration, Appropriable Quasi-Rents, and the Competitive Contracting Process, Journal of Law and Economics, 21 (October), 297-325.

Kobrin, Stephen J. (1976), The Environmental Determinants of Foreign Direct Manufacturing Investment: An Ex Post Empirical Analysis, Journal of International Business Studies, 7 (FallWinter), 29-42.

Kobrin, Stephen J., John Basek, Stephen Blank, and Joseph La Palombara (1980), The Assessment and Evaluation of Noneconomic Environments by American Firms: A Preliminary Report, Journal of International Business Studies, 11 (Spring-Summer), 32-46.

Lall, Sanjaya (1978), The Pattern of Intra-Firm Exports by U.S. Multinationals, Oxford Bulletin of Economics and Statistics, 40 (August), 209-222.

Lee, Woo-Young and John J. Brasch (1978), The Adoption of Export as an Innovative Strategy, Journal of International Business Studies, 9 (Spring-Summer), 85-93.

Lilien, Gary L. (1979), ADVISOR 2: Modeling the Marketing Mix Decision for Industrial Products, Management Science, 25 (February), 191-204.

Mascarenhas, Briance (1982), Coping With Uncertainty in International Business, Journal of International Business Studies, 13 (Fall), 87,98.

Newbould, Gerald D., Peter J. Buckley, and Jane C. Thurwell (1978), Going International: The Experience of Smaller Companies Overseas, New York: John Wiley and Sons, Inc.

Nunnally, Jum C. (1978), Psychometric Theory, SecondEdition, New York: McGraw-Hill.

Puxty, Anthony G. (1979), Some Evidence Concerning Cultural Differentials in Ownership Policies of Overseas Subsidiaries, Management International Review, 19 (2), 39-52.

Richman, Barry M. and Melvyn Copen (1972), International Management and Economic Development, New York: McGraw-Hill.

Robinson, Richard C. (1978), International Business Management: A Guide to Decision Making, 2nd edition, Hinsdale, Ill.: The Dryden Press

Robock, Stefan H., Kenneth Simmonds, and Jack Zwick (1977), International Business and Multinational Enterprises, Howmewood, lll.: Richard D. Irwin.

Root, Franklin J. (1983), Foreign Market Entry Strategies, New York: AMACON.

Rugman, Alan M. (1982), New Theories of the Multinational Enterprise, New York: St. Martin's Press. 
Rummel, R.J. and David A. Heenan (1978), How Multinationals Analyze Political Risk, Harvard Business Review, 56 (January-February), 67-76.

Seidler, Lee J. (1972), Nationalism and the International Transfer of Accounting Skills. In A. Kapoor and Phillip D. Grubb, eds., The Multinational Enterprise in Transition, 233-242, Princeton: The Darwin Press.

Shetty, Y.K. (1979), Managing the MNC: European and American Styles, Management International Review, 19 (3), 39-48.

Stern, Louis W. and Adel El-Ansary (1982), Marketing Channels, Englewood Cliffs, N.J.: Prentice Hall.

Stopford, John M. and Louis T. Wells, Jr. (1972), Managing the Multinational Enterprise, New York: Basic Books.

Teece, David J. (1983), Technological and Organizational Factors in the Theory of the Multinational Enterprise. In Mark Casson, ed., The Growth of International Business, 51-62, New York: George Allen and Irwin.

(1976), The Multinational Corporation and the Resource Cost of International Technology Transfer, Cambridge: Ballinger Publishing.

Telesio, P. (1979), Technology Licensing and Multinational Enterprises, New York: Praeger.

Time (1981), Big Mac Attack, (September 14), 56.

Vernon, Raymond (1983), Organizational and Institutional Responses to International Risk. In Richard J. Herring, ed., Managing International Risk, 191-216, Cambridge:Cambridge University Press.

(1977), Storm Over the Multinationals, Cambridge: Harvard University Press.

(1966), International Trade and International Investment in the Product Life Cycle, Quarterly Journal of Economics, (May), 190-207.

and Louis T. Wells (1976), Manager in the International Economy, Englewood Cliffs, N.J.: Prentice Hall.

Walker, Gordon and David Weber (1984), A Transaction Cost Approach to Make-or-Buy Decisions, Administrative Science Quarterly, 29 (September), 373-391.

Weichmann, Ulrich and L. Pringle (1979), Problems that Plague Multinational Marketers, Harvard Business Review, 57 (4), 118-124.

Weinstein, Arnold K. (1974), The International Expansion of U.S. Multinational Advertising Agencies, MSU Business Topics, 10 (Summer), 29-35.

Weston, J. Fred and Bart W. Sorge (1972), International Managerial Finance, Homewood, Ill.: Richard D. Irwin.

Williamson, Oliver E. (1985), The Economic Institutions of Capitalism, New York: Free Press. (1983), Credible Commitments: Using Hostages to Support Exchange, American Economic Review, 83 (September), 519-540.

(1981a), The Economics of Organization: The Transaction Cost Approach, American Journal of Sociology, 87 (3), 548-577.

(1981b), The Modern Corporation: Origins, Evolution, Attributes, Journal of Economic Literature, 19 (December), 1537-1568.

(1979), Transaction Cost Economics: The Governance of Contractual Relations, Journal of

Law and Economics, 22 (October), 233-62.

Press.

(1975), Markets and Hierarchies: Analysis and Antitrust Implications, New York: The Free

Wilson, Brent D. (1980), The Propensity of Multinational Firms to Expand Through Acquisitions, Journal Of International Business Studies, 11 (Spring-Summer), 59-65.

Wind, Yoram and Howard Perlmutter (1977), On the Identification of Frontier Issues in International Marketing, Columbia Journal of World Business, 12 (Winter), 131-139.

Wind, Yoram, Susan P. Douglas, and Howard V. Perlmutter (1973), Guidelines for Developing International Marketing Strategies, Journal of Marketing, 37 (April), 14-23. 